\title{
Cuerpo extraño intravesical
}

\author{
Sánchez Zalabardo D, Cuesta Presedo JM. \\ Servicio de Urologia. Fundación Hospital Calahorra. La Rioja.
}

Actas Urol Esp. 2006; 30 (6): 646

$\mathrm{P}$ aciente colombiano de 45 años que como único antecedente de interés, refiere sondaje vesical hace 2 años por síndrome miccional irritativo. Ante la aparición de clínica similar a la de hace 2 años y ante el miedo al sondaje uretrovesical, el paciente introduce un cale eléctrico por la uretra "para intentar vaciar la vejiga". Ante la pérdida del cabo uretral y su intento infructuoso de recuperarlo, acude a Urgencias.

Se realiza extracción endoscópica de $80 \mathrm{~cm}$ de cable eléctrico. Tras ser interrogado repetidamente, el paciente niega cualquier actividad

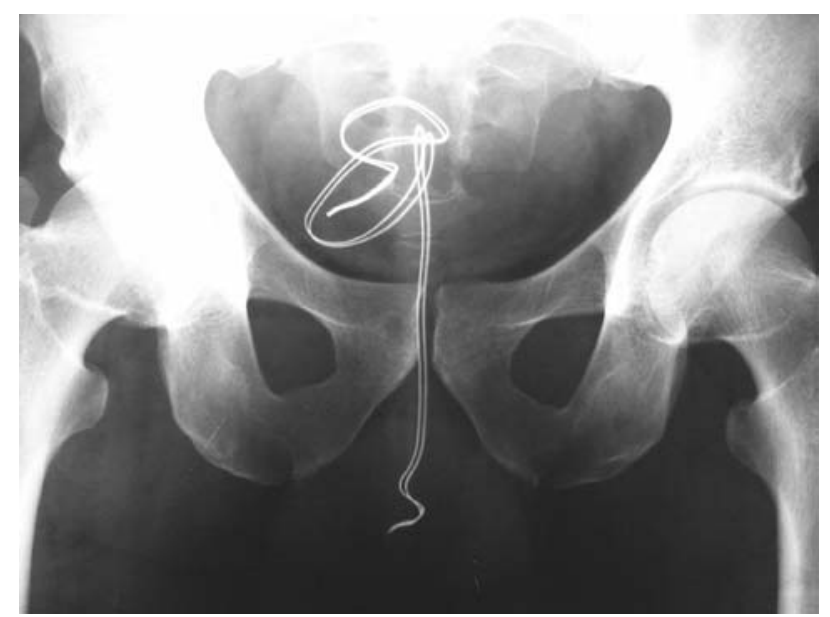

FIGURA 1. Radiografia de pelvis realizada en Urgencias. sexual relacionada con la introducción del cuerpo extraño. El paciente es dado de alta con cobertura antibiótica.

Dr. D. Sánchez Zalabardo

Fundación Hospital Calahorra

Carretera Logroño s/n

26500 Calahorra (La Rioja)

E-mail: dsanchez@fhcalahorra.com

(Trabajo recibido el 31 de agosto 2005)

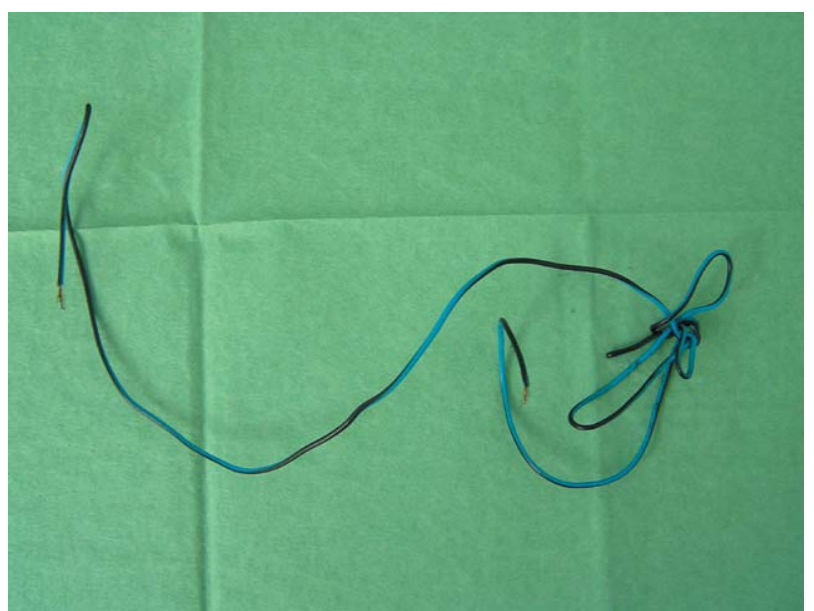

FIGURA 2. Aspecto del cable tras su extracción endoscópica 